\title{
Mapping of the Cadmium Lead and Mercury in Rice of Paddy Fields Within a CKDu Hotspot in Sri Lanka
}

\author{
T. B. Ananda Jayalal* \\ Date Received: $10^{\text {th }}$ September 2019 / Date Accepted: 01 ${ }^{\text {st }}$ February 2020
}

\begin{abstract}
Purpose : Evidence of substantial levels of chronic exposure to heavy metals from food has emerged in a number of studies carried out in the recent past. The contamination of rice, the main dietary staple, is attributed in the main source to this chronic toxicity. Determining of source and magnitude of such contamination will assist to propose suitable public health interventions.

Research Method: The area with the second highest prevalence of Chronic Kidney Disease of uncertain aetiology (CKDu) in Sri Lanka; Padaviya Divisional Secretariat area paddy fields were selected for the study. Paddy samples were collected from cross-section of locations with GPS locations, intended to represent the entire field. Paddy was processed for rice by routine methods. The fields were rain fed or irrigation fed, this being duly noted.

Findings : Analytical results were expressed on a wet matter basis. Mercury was not detected in any of the 196 samples. Out of 196 rice samples, 21 (11\%) had no detectable levels of lead or cadmium. Seventeen (9\%) samples contained cadmium exceeding $50 \mu \mathrm{g} / \mathrm{kg}$ and lead exceeding $100 \mu \mathrm{g} / \mathrm{kg}$. The minimum, maximum and mean lead levels in rice were 50, 790, $118 \mu \mathrm{g} / \mathrm{kg}$ respectively. Minimum, maximum and mean cadmium levels in rice were 30, 280,33 $\mathrm{gg} / \mathrm{kg}$ respectively. Lead contamination appeared to be an equally widespread issue in the tested irrigation water fed paddy fields. However, determined lead concentrations are significantly lower in rain-fed fields. Cadmium contamination seems to be significantly greater in the rain-fed fields than in irrigation-fed fields.

Originality/Value: The magnitude of contamination of potential nephrotoxic heavy metals and its geospatial distribution in rice which is the main staple diet of people living around the studied paddy field where second highest CKDu prevalence were reported, and have been revealed. The information generated can be utilized to reduce the contaminant levels by agronomic practices and diet based public health intervention to reduce the human exposure.
\end{abstract}

Keywords: Chronic Kidney Disease, cadmium, lead, mercury, rice

\section{INTRODUCTION}

Consumption of contaminated food with heavy metals is thought to be causally associated with chronic kidney disease of uncertain aetiology of Sri Lanka. Evidence of chronic low levels of exposure to heavy metals from food in Sri Lanka has emerged in a number of studies carried out in the recent past (Bandara JMRS et al., 2008, Bandara JM et al., 2010, Bandara JM et al., 2011, Chandrajith R et al., 2011, Meharg AA et al., 2013, Jayattilake N et al., 2013, Levine KE et al., 2016, Diyabalanage S et al., 2016, Jayalal TBA et al., 2019).
Human exposure to toxic heavy metals is considered as a serious public health concern in most developed countries. However, Sri Lanka, which is a small tropical island nation with low economic status, with limited research capabilities, has not given adequate emphasis on the contaminants in food and their associated risks to public health. Moreover, dietary habits

\footnotetext{
Ministry of Health, Nutrition and Indigenous Medicine, Colombo, Sri Lanka.

jayalal313@yahoo.co.uk

(1) ORCID http://orcid.org/0000-0002-2814-1820 
of Sri Lankans in general are distinctly different from most of its global counterparts (World Health Organization 2018), thereby warranting a deeper evaluation of the situation. Sri Lanka is categorized in the G14 cluster of global dietary consumption groups according to the WHO GEMS diet categorizations (World Health Organization 2018). Other countries included in this cluster are; Comoros, Fiji Islands, Kiribati, Papua New Guinea, Solomon Islands and Vanuatu (World Health Organization 2018). A common feature among this cluster of countries is the high consumption of cereals, especially rice, in their diets. A dietary survey among $\mathrm{CKDu}$ affected families have revealed that CKDu affected adults consume $2.5 \mathrm{~kg}$ of rice and less than $1 \mathrm{~kg}$ of vegetables per week (Jayalal TBA et al., 2019) and very low intake of food of animal origin. Because of this peculiar food preference and habit, a reasonable evaluation of contaminants in rice demands priority attention. Analysing of contaminants in question have not been reported with the necessary rigor in order to quantify the contaminants levels in and trace them back to geographical locations. Such data will be useful to understand the magnitude of the issue and help in formulating effective public health interventions to minimize the adverse exposures.

Chronic exposure to cadmium and lead have been associated with chronic renal failure among other health outcomes (World Health Organization 1992, 1995). Cadmium and lead exposure through food has been identified as the main mode of exposure in non-occupational settings (World Health Organization; (2011). Common mechanisms in nephropathy induced by toxic metals are described by Sabolić I (2006); Pizzino G et al., (2014).

An increased risk of nephropathy was noted in workers with lead blood levels over $3.0 \mu \mathrm{mol} / \mathrm{L}$ (World Health Organization 1995). The European Union Food Safety Agency has developed dose response models for chronic lead exposure from food, resultant blood lead levels from consuming such food, and quantified the corresponding increase in systolic blood pressure, the corresponding decrease in glomerular filtration rate and intelligence quotient (European Food
Safety Authority 2018). Accordingly, lead exposure from food is a public health concern.

Chronic low-level exposure to lead and cadmium have been hypothesized as risk factors in not only CKDu but also in neuro-developmental defects in children, hypertension in adults, neoplasms, low birth weight and malnutrition in various studies (Allen KA. 2015, Taylor CM, et al., 2015, Adams S V. et al., 2012, García-Esquinas E. et al., 2014, Wai KM. et al., 2017, Huang K, et al., 2016, Johnston JE, et al., 2014). Further synergistic effect of cadmium and lead on nephrotoxicity has been described in the scientific literature (World Health Organization 2011; Ana Navas-Acien et al., (2019).

Jayathilake $\mathrm{N}$ et al., (2013) comparing CKDu afflicted population and healthy controls, have shown statistically significant different high urine excretion of cadmium in $\mathrm{CKDu}$ patients again indicating the possible exposure.

Lead and cadmium have been detected in Sri Lankan food samples (Bandara JMRS et al., 2008, Bandara JM et al., 2010, Bandara JM et al., 2011, Chandrajith R et al., 2011, Meharg AA et al., 2013, Jayattilake N et al., 2013, Levine KE et al., 2016, Diyabalanage S et al., 2016). Blood lead levels in similarly affected people had been reported by Levine KE et al., (2016), and Jayalal TBA et al., (2019). Further, a comprehensive exposure assessment of lead and cadmium through food has been done by Jayalal TBA et al., (2019).

Among the heavy metals of concern, cadmium and lead were selected for the study as they are known to cause chronic kidney damage (World Health Organization 1992, 1995, 2011; European Food Safety Authority 2018). Mercury was also included in the analysis as Levine KE et al., (2016) have reported that the population in the North Central Province (NCP) is subjected to chronic, low level exposure to three nephrotoxic elements - cadmium, lead and mercury. Levine KE et al., (2016) have reported a mean of 36ug/ $\mathrm{kg}$ mercury in rice. Further, it had been reported that hair mercury levels of people living in study area exceeded US mean reference values for women of child bearing age in $66.1 \%$ of the samples. 
The objective of the study was to determine lead, cadmium and mercury levels in rice samples collected from paddy fields of Padaviya area and mapping of the data.

\section{MATERIALS AND METHODS}

\section{Study design}

This study is a cross sectional study of quantitative analysis of selected heavy metals, (lead, cadmium and mercury) in rice samples collected from the identified rice fields.

\section{Study setting}

Paddy fields of Padaviya Divisional Secretariat area were selected for the study. This area reported the second highest prevalence of $\mathrm{CKDu}$ in Sri Lanka (Ministry of Health Nutrition and Indigenous Medicine 2016 ("unpublished") so to capture the potentially worst-case scenario. Total paddy lands were identified by a research assistant who was well acquainted with the area and using google maps. According to the irrigation department, 18,500 acres (75 square kilometers) of land is irrigated by the Padaviya tank. One hundred and ninety six samples were collected from various parts of the fields in order to represent the whole field. As the objective was to map the contaminants, the study size was estimated by collecting at least two samples from each square kilometer of the fields under study. Samples were collected from fields being harvested to represent the total area of the fields to the greatest possible extent. Some fields were skipped as harvesting had not begun.

GPS locations of sample collection points of the paddy field were obtained using google maps by a person who is well acquainted with the area. The data on water supply; if rain fed or irrigation fed was also noted. Approximately $10 \mathrm{~g}$ of paddy was collected to clean plastic containers and sun dried. Samples were collected during late February and March 2018 which was the harvest of the Maha season. Thereafter, the samples were steamed, dried in the laboratory and husked manually as done by the farmers in rice processing.

Samples were collected in clean plastic containers, stored in wet state under refrigerated conditions and transported to laboratory. All samples were analyzed by SGS Lanka (Pvt) Limited, Colombo 2. About $0.5 \mathrm{~g}$ of the homogenized samples were digested using Mars Xpress microwave digester (CEM; Matthews, NC). Digestion was performed with $5 \mathrm{ml}-10 \mathrm{ml} \mathrm{HNO}_{3}(69.0 \%$ extra pure; SRL, India) diluted to $50 \mathrm{ml}$ using deionized water. Concentration of trace elements cadmium, lead and mercury were determined using Thermo ICapQ (Thermo-Fisher Scientific Inc., Bremen, Germany) machine by Inductively Coupled Plasma Mass Spectrometry (ICP-MS) method. Multi-element ICP-MS standards (AccuStandard, USA) were used for the instrumental calibration. Six Standards of 1, 2, 5, 10, 20 and $50 \mathrm{ug} / \mathrm{L}$ were used for the calibration. Limit of quantification (LOQ) for $\mathrm{HNO}_{3}$ digested analyte were 0.0006 $\mathrm{mg} / 1,0.0003 \mathrm{mg} / 1,0.001 \mathrm{mg} / \mathrm{ml}$ for lead, cadmium and mercury respectively. Analytical results were expressed on wet matter basis.

All statistical analyses were performed by Excel and SPSS ver. 23.0. Non parametric test (Mann Whitney U test) was used to find the significance of statistical difference between rain fed and irrigation fed paddy fields' lead and cadmium levels.

\section{Ethical considerations}

The protocol was approved by the Ethics Committee of the Medical Research Institute, Sri Lanka (Project No. 42/2016). Informed consent was obtained from the owners of the field to collect samples.

\section{RESULTS AND DISCUSSION}

Mercury was not detected in any of the samples.

Out of 196 rice samples 21 (11\%) had no detectable levels of lead or cadmium. Seventeen 
(9\%) samples contained both contaminants, cadmium exceeding $50 \mu \mathrm{g} / \mathrm{kg}$ and lead exceeding $100 \mu \mathrm{g} / \mathrm{kg}$. The minimum maximum and mean lead in rice were $50,790,118 \mu \mathrm{g} / \mathrm{kg}$ respectively. Table 01 categorizes the Lead contamination into three groups according to contamination level.Minimum, maximum and mean levels of cadmium were $30,280,33 \mu \mathrm{g} / \mathrm{kg}$ respectively. Table 02 shows the mean lead and cadmium concentrations of rice in paddy fields of rain fed or irrigation fed. Results show there is a statistically significant difference between mean lead and mean cadmium levels in rain fed and irrigation fed paddy fields.Figure 01A shows the magnitude of cadmium contamination of rice in each GPS location in the study area.Figure 01B shows the magnitude of lead contamination of rice in each GPS location in the study area.

\section{Water source and Irrigation system of Padaviya Tank.}

Padaviya tank receives water from monsoonal rain falling on the South Western part of the tank in the Anuradhapura district. There are two canals starting at coordinates 8.6952040, 80771010106 and $8.7552659,80.7336981$ which carry water from monsoonal rains to the tank. It is noteworthy that no irrigation system like the Mahaweli diversion or any other water source from central highlands of the country feeds this tank. Padaviya tank supplies water for farming in the North Eastern part of the tank in two canals. There are some paddy lands which are not provided water from those cannels due to higher elevation and those fields are cultivated from monsoonal rains directly.

Table 01: Lead contamination according to the level of contamination.

\begin{tabular}{cc}
\hline Lead concentration $\mu \mathrm{g} / \mathrm{kg}$ & Number of samples (percentage) \\
\hline Below LOQ & $38(19)$ \\
$50-99$ & $75(38)$ \\
$<100$ & $83(43)$ \\
Total & $196(100)$ \\
\hline
\end{tabular}

Table 02: Mean lead and cadmium concentrations versus water supply.

\begin{tabular}{lccc}
\hline & Rain Fed & Irrigation fed & p value \\
\hline Number of samples & 18 & 178 & \\
Mean lead $\mu \mathrm{g} / \mathrm{kg}$ & 84 & 121 & 0.000 \\
Mean cadmium $\mu \mathrm{g} / \mathrm{kg}$ & 112 & 25 & 0.045 \\
\hline
\end{tabular}

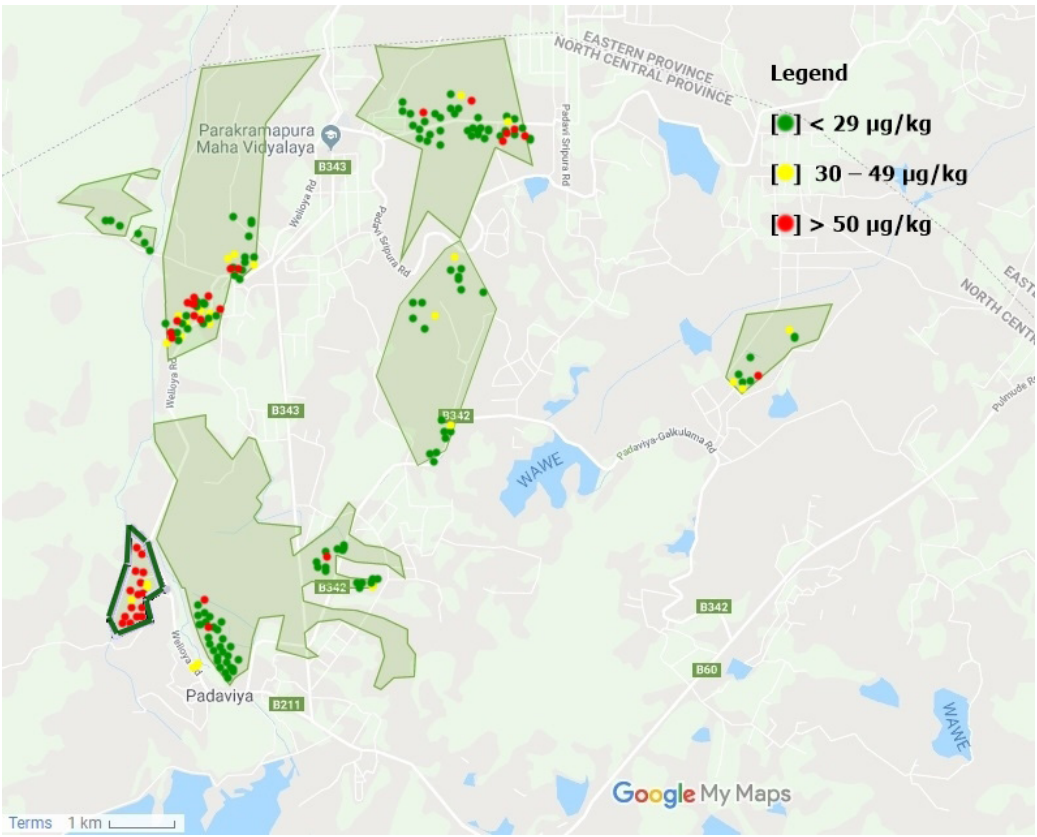

Rain fed field border is marked in green.

Figure 01A: GPS Map of cadmium contamination in rice of study area. 


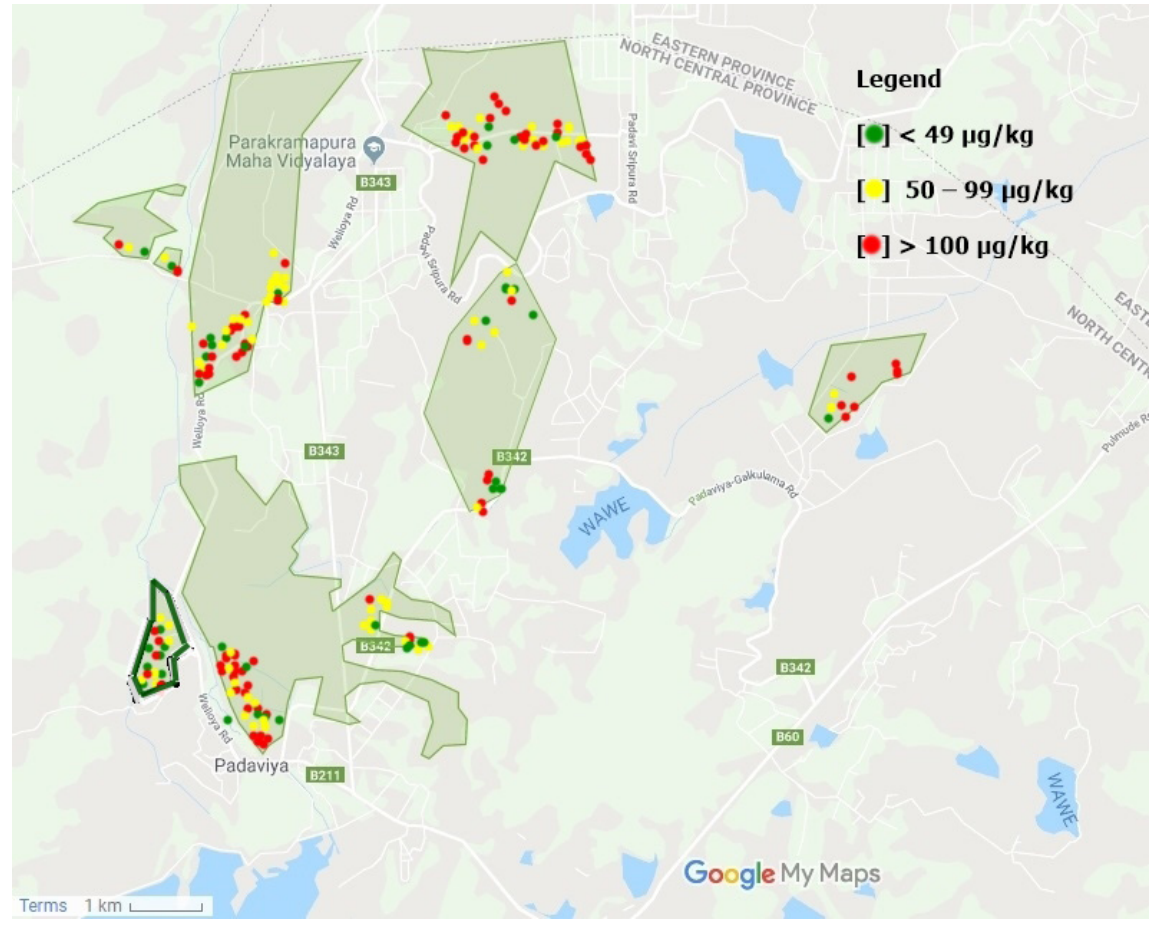

Rain fed field border is marked in green.

Figure 01 B: GPS Map of lead contamination in rice of study area.

\section{Contaminants in food samples}

As described by Jayalal TBA et al., (2019) rice and vegetables collected from the households of the area are also equally contaminated with lead and cadmium. Further, consumption pattern of food in this area has been modeled as three kilograms of rice, one kilogram of vegetables and negligible amounts of food of animal origin for an average $60 \mathrm{~kg}$ man per week. Accordingly, in a such exposure model the reported lead contamination may cause adverse health outcomes that would be of public health concern. Levine et al., (2016) and Jayalal et al., (2019), have shown considerable levels of blood lead in the inhabitants of the area adding further supportive evidence for lead exposure. The health impacts of such exposure, as described by the CONTAM panel of European Food Safety Authority (2018) are: increase in systolic blood pressure, decrease in intelligence quotient and decrease in glomerular filtration rate. Those health risks have been quantified for the population living in this area by Jayalal et al., (2019). This seems to be of serious public health concern. The information generated in this study reaffirms the clinically significant wider contamination of main staple food by lead reported previously. The phenomenon of fluoride being associated with increased absorption of lead may serve to exacerbate the effects of lead in this situation as it had been reported that fluoride concentration in water in the $\mathrm{CKDu}$ affected areas is high Ranasinghe $\mathrm{N}$ et al., (2018).

Cadmium contamination seems to be compatible with previous finding of the Jayalal et al., (2019) in the area and the detected levels may cause health issues in vulnerable population sub groups. Further, it has been reported that cadmium and lead have synergistic effects. Therefore, cadmium also needs to be considered as a potentially significant contaminant found in rice which can cause health impacts.

There is a difference in contamination of rice by lead and cadmium in irrigation and rain fed fields. Lead contamination appeared to be widespread in the tested irrigation water fed fields paddy fields according to the GPS mapping. However, in contrast, determined lead concentrations are lower in rice from rain fed fields. The observed difference is statistically significant. Furthermore, cadmium contamination seems to be higher in the rice coming from rain fed fields than in irrigation water fed fields. The observed difference is statistically significant. Further follow up research may be required to understand the reasons for those observed differences. 
The lead content in rice seems to be of concern since most of the people living in the vicinity consume it as the major staple in their diet. The contamination seems to be widespread across the paddy lands in this study, except there were few areas of low contamination. Rain fed paddy fields seem to be less contaminated with lead; however, cadmium contamination seems to be more serious in rain fed fields. Irrigation fed areas' rice seem to be moderately contaminated with cadmium.

Wijewardhana et al., (2016) in their review on heavy metal pollution in Sri Lanka have shown lead contamination in agricultural soil, calculated index values vary from 21 to 32 . In contrast, in non-agricultural soil it is reported 13 to 19 . They have reported $79.2 \mathrm{mg} / \mathrm{kg}$ of lead and $4 \mathrm{mg} / \mathrm{kg}$ of cadmium in Triple Super Phosphate (TSP) fertilizer in samples collected from Madawachchiya. Therefore, conclusion of natural presence of heavy metals in the soil being augmented by chemical fertilizers, climatic condition and physical environment may play a role in absorption of those contaminants to plants leading to their presence in food.

The study was limited to a selected geographical region and therefore, may not be taken as generic to all CKD affected areas.

It is recommended to bring down the lead and cadmium concentration in the rice to the lowest possible level to reduce the adverse health impacts. Alternatively, or in combination, appropriate dietary intervention e.g. increasing the proportion of food of animal meat or fish, both of which are believed to be less contaminated with lead and cadmium also recommended to reduce the potentially harmful exposures. Further research on how to reduce the contaminants in rice and food are necessary. Continuous monitoring of lead and cadmium with other potential contaminants in the food should be undertaken. Effective advocacy programmes aimed at modifying the dietary habits of people living in the area should be considered necessary in light of this study.

\section{Authors' Statement of Any Conflicts of Interest and Acknowledgment of Sources of Funding}

The author declare that he has no competing interests. The study was funded by Second Health Sector Development Project of World bank component II.

\section{Data Availability statement}

The datasets used and/or analysed during the current study are available from the corresponding author on reasonable request.

\section{REFERENCES}

Adams, S. V. Passarelli, M.N. \& Newcomb, P.A. (2012). Cadmium exposure and cancer mortality in the Third National Health and Nutrition Examination Survey cohort. Occupational and Environmental Medicine. 69 (2), pp. 153-6. DOI: 10.1136/oemed-2011-100111

Allen, K.A. (2015). Is prenatal lead exposure a concern in infancy? What is the evidence? Advances in Neonatal Care. 15 (6), pp. 416-20. DOI: 10.1097/ANC.0000000000000224.

Bandara, J.M. Wijewardena, H.V. Liyanege, J. Upul, M.A. Bandara, \& J.M.U.A. (2010). Chronic renal failure in Sri Lanka caused by elevated dietary cadmium: Trojan horse of the green revolution. Toxicology Letters. 198, pp.33-39. DOI: 10.1016/j.toxlet.2010.04.016.

Bandara, J.M. Wijewardena. H.V. Bandara, Y,M. Jayasooriya, R.G. \& Rajapaksha, H. (2011). Pollution of River Mahaweli and farmlands under irrigation by Cadmium from agricultural inputs leading to a chronic renal failure epidemic among farmers in NCP, Sri Lanka. Environmental Geochemistry and Health. 33(5), pp. 439-453. DOI: 10.1007/s10653-010-9344-4. 
Bandara, J.M.R.S. Senevirathna, D.M.A.N. Dasanayake, D.M.R.S.B. Herath, V. Bandara. J.M.R.P. Abeysekara. T. \& Rajapaksha, K.H. (2008). Chronic renal failure among farm families in cascade irrigation systems in Sri Lanka associated with elevated dietary cadmium levels in rice and freshwater fish (Tilapia). Environmental Geochemistry and Health. 30(5), pp. 465-78. DOI: $10.1007 / \mathrm{s} 10653-007-9129-6$

Chandrajith, R. Nanayakkara, S. Itai, K. Aturaliya, T.N.C. Dissanayake, C.B. Abeysekera, T. Harada, K. Watanabe, T. \& Koizumi, A. (2011). Chronic kidney diseases of uncertain etiology $(\mathrm{CKDu})$ in Sri Lanka: geographic distribution and environmental implications. Environmental Geochemistry and Health. 33(3), pp.267-278. DOI:10.1007/s10653-010-9339-1

Diyabalanage, S. Navarathna, T. Abeysundara, H.T. Rajapakse, S. \& Chandrajith, R. (2016). Trace elements in native and improved paddy rice from different climatic regions of Sri Lanka: implications for public health. Springer Plus. 5(1), DOI: 10.1186/s40064-016-3547-9

EFSA Panel on Contaminants in the Food Chain (CONTAM) (2010). Scientific Opinion on Lead in Food. EFSA Journal. 8(4), pp. 151. DOI:10.2903/j.efsa.2010.1570

García-Esquinas, E. Pollan, M. Tellez-Plaza. M. Francesconi, K.A. Goessler, W. Guallar, Umans, J.G. Yeh, J. Best, L.G. \& Navas-Acien A. (2014). Cadmium exposure and cancer mortality in a prospective cohort: The strong heart study. Environmental Health Perspectives. 122 (4), pp.363-70 DOI: 10.1289/ehp.1306587

George, W. \& Latimer, Jr. (2012). Official Methods of Analysis of AOAC International. 19 $9^{\text {th }}$ Edition. AOAC International, Maryland, USA.

Huang, K. Li, H. Zhang, B. Zheng, T. Li, Y. Zhou, A. Du, X. Pan, X. Yang, J Wu, C. Jiang, M. Peng, Y. Huang, Z. Xia, W. \& Xu, S. (2016). Prenatal cadmium exposure and preterm low birth weight in China. Journal of Exposure Science \& Environmental Epidemiology. 27(5), pp. 491-6. DOI: $10.1038 /$ jes.2016.41

Jayalal, T.B. Bandara, J.T.W.M.A. Mahawitha, S.T.C. Wansapala, J.M.A. \& Galappaththi. S.P.L. (2019). A quantitative analysis of chronic exposure of selected heavy metals in a model diet in a CKD hotspot in Sri Lanka, BMC Nephrology. 20(1) pp.1 - 14. DOI:10.1186/s12882-019$1371-5$

Jayatilake, N. Mendis, S. Maheepala, P. \& Mehta, F.R. (2013). Chronic kidney disease of uncertain aetiology: Prevalence and causative factors in a developing country. BMC Nephrology. 14, pp. 1-13. DOI: $10.1186 / 1471-2369-14-180$.

Johnston, J.E. Valentiner, E. Maxson, P. Miranda, M.L. \& Fry, R.C. (2014) Maternal cadmium levels during pregnancy associated with lower birth weight in infants in a North Carolina cohort. PLoS One. 9(10), DOI: 10.1371/journal.pone.0109661

Levine, K.E. Redmon, J.H. Elledge, M.F. Wanigasuriya, K.P. Smith, K. Munoz, B. Waduge, V.A. Periris-John, R.J. Sathiakumar, N. Harrington, J.M. Womack, D.S. \& Wickremasinghe, R. (2016). Quest to identify geochemical risk factors associated with chronic kidney disease of unknown etiology $(\mathrm{CKDu})$ in an endemic region of Sri Lanka - a multimedia laboratory analysis of biological, food, and environmental samples. Environmental Monitoring and Assessment. 188 (10), pp. 548. DOI: 10.1007/s10661-016-5524-8. 
Meharg A.A. Norton, G. Deacon, C. Williams, P. Adomako, E.E. Price, A. Zhu, Y. Li, G. Zhao, F.J. McGrath, S. Villada, A. Sommella, A. De Silva, P.M. Brammer, H. Dasgupta, T. \& Islam M.R. (2013). Variation in rice cadmium related to human exposure. Environmental Science and Technology. 47 (11), pp. 5613 - 5618. DOI:10.1021/es400521h

Navas-Acien, A. Tellez-Plaza, M. Guallar, E. Muntner, P. Silbergeld, E, Jaar, B. \& Weaver, V. (2009). Blood Cadmium and Lead and Chronic Kidney Disease in US Adults: A Joint Analysis. American Journal of Epidemiology. 170(9), pp. 1156-1164. DOI: 10.1093/aje/kwp248.

Pizzino, G. Bitto, A. Interdonato, M. Galfo, F. Irrera, N. Mecchio, A. Pallio G.1. Ramistella, V. De Luca, F. Minutoli, L. Squadrito, F. \& Altavilla, D. (2014). Oxidative stress and DNA repair and detoxification gene expression in adolescents exposed to heavy metals living in the Milazzo-Valle del Mela area (Sicily, Italy). Redox Biology. 2, pp. 686-93. DOI:10.1016/j.redox.2014.05.003

Ranasinghe, N. Kruger, E. Chandrajith, R. \& Tenent, M. (2018). Groundwater fluoride in Sri Lanka: Opportunities to mitigate the risk at maximum contaminant level. Ceylon Medical Journal. 63, pp. 174-179. DOI: http://doi.org/10.4038/cmj.v63i4.8768

Sabolić, I. (2006). Common mechanisms in nephropathy induced by toxic metals. Nephron Physiology. 104(3), pp.107-14. DOI:10.1159/000095539

Taylor, C.M. Golding, J. \& Emond, A.M. (2015). Adverse effects of maternal lead levels on birth outcomes in the ALSPAC study: A prospective birth cohort study. BJOG An International Journal of Obstetrics and Gynaecology. 122 (3), pp. 322 -328. DOI: 10.1111/1471-0528.12756

Wai, K.M. Mar, O. Kosaka, S. Umemura, M. \& Watanabe, C. (2017) Prenatal heavy metal exposure and adverse birth outcomes in Myanmar: A birth-cohort study. International Journal of Environmental Research and Public Health. 14 (11), pp. 1339. DOI: 10.3390/ijerph14111339.

Wijayawardhana D, Herath V, \& Weerasinghe A, (2016). Heavy Metal pollution in Sri Lanka with special reference to agriculture: A review of current research evidences. Rajarata University Journal. 4(1), pp. 52-66.

World Health Organization (2012). Tracking contaminants in food. Available from: http://www.who. int/foodsafety/areas_work/chemical-risks/gems-food/en/ (accessed on 30 August 2018)

World Health Organization, (1992). Environmental Health Criteria 134: Cadmium. World Health Organization, Geneva.

World Health Organization, (1995). Environmental Health Criteria 165: Lead. World Health Organization, Geneva.

World Health Organization, (2011). Safety Evaluation of certain food additives and contaminants: seventy-third report of the Joint FAO/WHO Expert Food additives. World Health Organization, Geneva. 305 - 497 